\title{
The Influence of the Chemical Compounds on the Zinc Oxide Nanostructures Growth in Chemical Bath Deposition
}

\author{
M. Byrczek, M. Malewicz, G. Halek and H. Teterycz \\ Faculty of Microsystem Electronics and Photonics, Wrocław University of Technology \\ Janiszewskiego 11/17, 50-372 Wrocław, Poland
}

\begin{abstract}
In this paper, the results of the investigation the growth of the zinc oxide nanocrystals during chemical bath deposition will be presented. The influence of the chemical compounds on the shape and the composition of the nanostructures were researched. Chemical compounds like hexamethylenetetramine, zinc nitrate hexahydrate, urea and ascorbic acid were used in experiments.
\end{abstract}

PACS numbers: 81.07.Bc

\section{Introduction}

The nanostructures have special properties, which are caused by their dimensions. In such a nanostructure like e.g. nanorod or nanotube, the Debye length is similar to the structure's diameter. In this kind of nanostructures almost every atom can be considered as surface atom. This fact increases the speed and efficiency of the surface reactions. Practical application of $1 D$ nanostructures can improve the efficiency of gas sensors, solar cells and heterogeneous catalysts.

Zinc oxide because of its properties, like wide band-gap $(3.37 \mathrm{eV})$ and small extension binding $(60 \mathrm{meV})[1]$ have been widely investigated in the last decade. There are many articles about methods of synthesis of $\mathrm{ZnO} 1 \mathrm{D}$ nanostructures synthesis methods $[2,3]$. The zinc oxide can be obtained using several techniques like PVD, CVD or wet chemistry. One of the most interesting method of $\mathrm{ZnO}$ synthesis is chemical bath deposition (CBD). It does not need complicated and expensive instruments and it allows for deposition of $\mathrm{ZnO}$ on different substrates. In literature there are described plenty of experiments, which show the possibilities of synthesis of different nanostructures $[4,5]$, but there is no systematic investigations, which completely describe the influence of the process parameters on the shape and dimensions of the nanostructures in CBD [6-8].

The aim of our work is to develop the method, which allows us to obtain the nanotubes and nanorods with changing diameter for application in gas sensors, photocatalysis and as an antiseptic material. Because there is no systematic investigation about how process parameters affect $\mathrm{ZnO}$ nanocrystals growth, we have started to work on the complex characterization of the influence of the substrate preparation, temperature, time of heating [9-11], chemical compounds, electrical field, microwave on the shape and size of the nanostructures. In this paper we present the results of our investigation of the in- fluence of chemical compounds and their impact on the quality of the nanomaterials.

\section{Experimental part}

The deposition of $\mathrm{ZnO}$ was carried out in the process of CBD. For this investigation the aqueous solution of the nonorganic zinc compound and organic precipitating reagent were used. The $\mathrm{ZnO}$ nanostructures were deposited on the glass substrate covered with thin layer of indium tin oxide (ITO) with resistivity $10 \Omega /$ sq. The ITO glass substrate was cleaned in the heated mixture of high purity water and hydrogen peroxide $30 \%$ for $10 \mathrm{~min}$, and then it was placed in the glass beaker filled with deposition solution. The solution for deposition process was prepared as the one described in paper [7].

To define the influence of the organic compound on the nanostructures, the three experiments with different compositions of organics reagents were done.

The first deposition process was conducted in typical conditions in $250 \mathrm{ml}$ of $100 \mathrm{mM}$ aqueous equimolar mixture of zinc nitrate hexahydrate $\left(\mathrm{Zn}\left(\mathrm{NO}_{3}\right)_{2} \cdot 6 \mathrm{H}_{2} \mathrm{O}\right)$ and hexamethylenetetramine $\left(\mathrm{HMT}, \mathrm{C}_{6} \mathrm{H}_{12} \mathrm{~N}_{4}\right)$ - sample A.

The second deposition process were made in the solution like the previous one, but $2.5 \mathrm{ml}$ of the $6 \mathrm{mM}$ ascorbic acid was added in to the solution, directly before putting the solution into the oven - sample B.

In the third experiment the organic compound HMT was replaced with urea $\left(\mathrm{CO}\left(\mathrm{NH}_{2}\right)_{2}\right)$. The molar concentration of the aqueous solution was kept at constant level. As in the second experiment, $2.5 \mathrm{ml}$ of the $6 \mathrm{mM}$ ascorbic acid was added into the solution directly before putting the solution into the oven - sample C.

The deposition process took $9 \mathrm{~h}$ and was carried out in the temperature of $95^{\circ} \mathrm{C}$. After the process was finished, the substrates were immersed in the isopropyl alcohol for $10 \mathrm{~h}$. 
The microstructure of $\mathrm{ZnO}$ was observed using the scanning electron microscope JOEL JSM-5800LV equipped with the X-ray microanalysis circuit by Oxford ISIS 300 with the semiconductor detector analyzing the energy of Röntgen $\mathrm{X}$ radiation.

The crystallographic structure of zinc oxide were determined using Philips Materials Research X-ray diffractometer (MRD) with $\mathrm{Cu} K_{\alpha}$ radiation.

\section{Results and discussion}

Our investigations with scanning electron microscopy (SEM) has revealed that the chemical compounds have a large influence on the nanostructure. The results of sample $\mathrm{A}, \mathrm{B}$ and $\mathrm{C}$ are shown in the pictures, respectively (Figs. 1-3). The sample $\mathrm{C}$ was totally different in comparison to the previous ones.

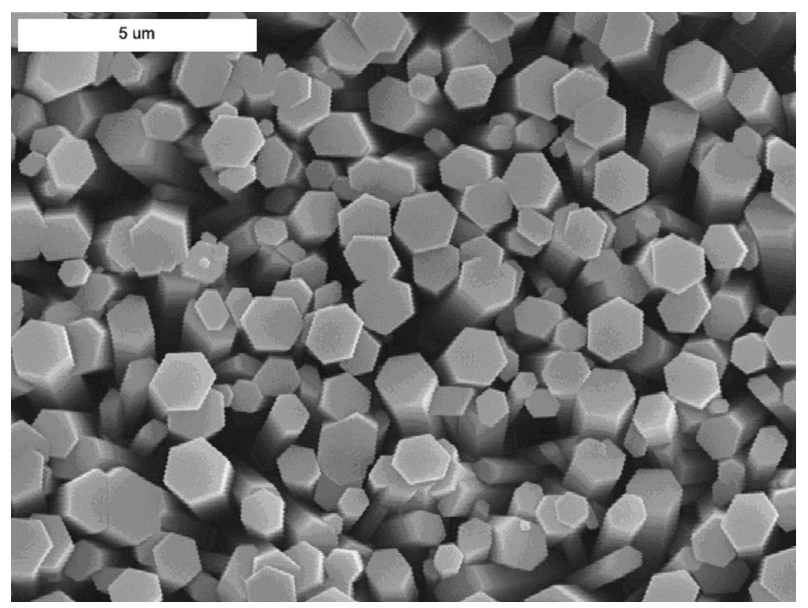

Fig. 1. SEM picture of sample A.

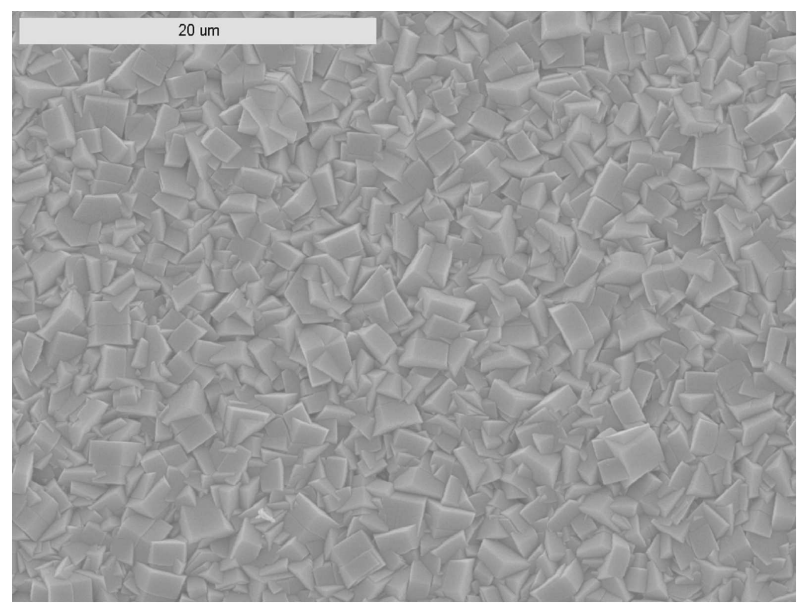

Fig. 2. SEM picture of sample B.

To identify the crystallinity and crystal phases of the as-grown structures, X-ray diffraction (XRD) analysis was performed and shown in Figs. 4-6. Figure 4 is a

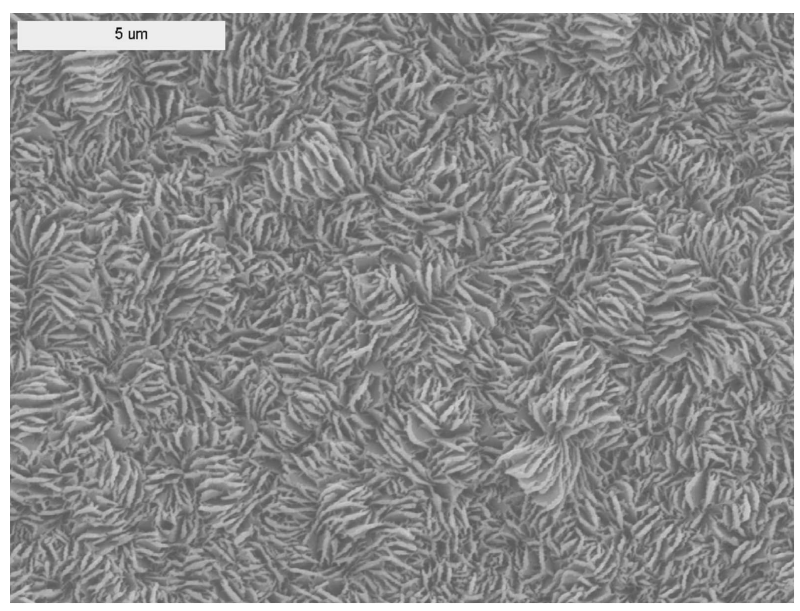

Fig. 3. SEM picture of sample C.

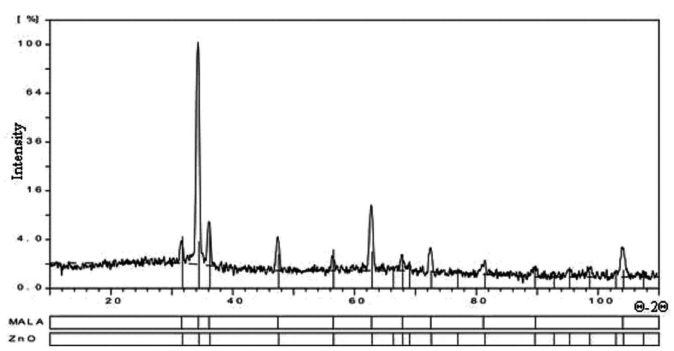

Fig. 4. XRD analysis of the sample A; the nanostructure obtained from the solution of $\mathrm{Zn}\left(\mathrm{NO}_{3}\right)_{2}$ and HMT.

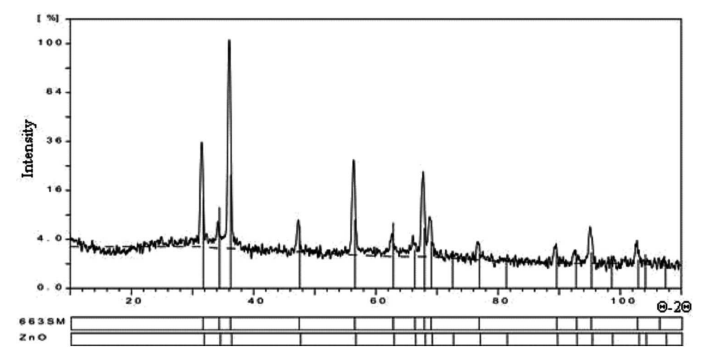

Fig. 5. XRD analysis of the nanostructure obtained from the solution of $\mathrm{Zn}\left(\mathrm{NO}_{3}\right)_{2}$, HMT and ascorbic acid.

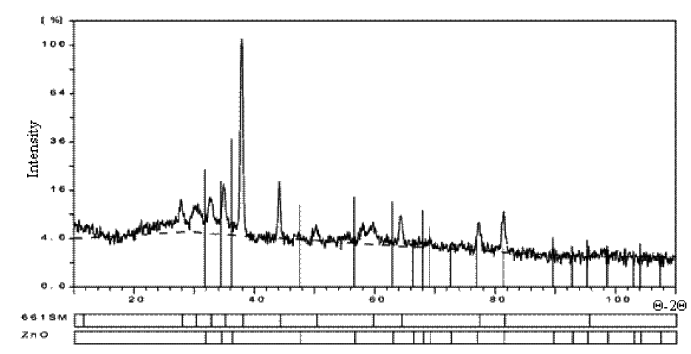

Fig. 6. XRD analysis of the nanostructure obtained from the solution of $\mathrm{Zn}\left(\mathrm{NO}_{3}\right)_{2}$, urea and ascorbic acid. 


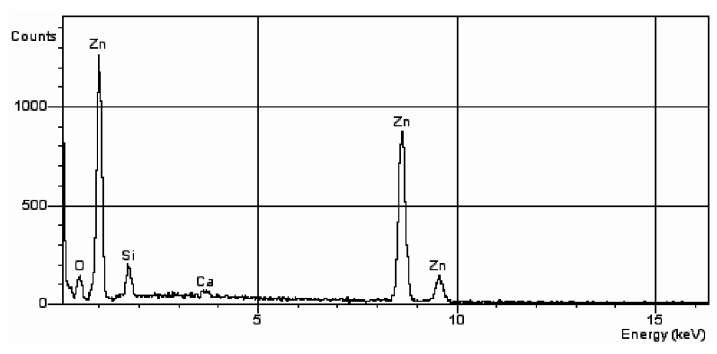

Fig. 7. EDX analysis of the sample A.

result for the sample $\mathrm{A}$. It shows the typical XRD pattern of the as-grown nanostructures on ITO substrate. All the peaks in the pattern can be indexed to hexagonal wurtzite structure with space group $P 6_{3} m c$ and lattice constants $a=0.3249 \mathrm{~nm}, c=0.5206 \mathrm{~nm}$ (JCPDS chart no. 36-1451). No diffraction peaks arising from any impurity can be detected in the pattern, which confirms that the grown products are pure $\mathrm{ZnO}$. The XRD result from the sample B is shown in Fig. 5. The XRD pattern of sample $\mathrm{C}$, it means obtained from zinc nitrate hexahydrate and urea, is totally different than XRD of pure $\mathrm{ZnO}$ (Fig. 6).

The investigation has shown the crystalline size. The average particle size and size distributions were determined for all the samples based on the full width and half maximum (FWHM) of the peaks and diffractometric profile analysis. AWPX software was used for this purpose. The single crystal average size is bigger than $1 \mu \mathrm{m}$. It can be assumed that single nanorod is a monocrystal. The same situation is with the sample B, but we can easily see that the layer is more dense.

The results from XRD are confirmed by the energy dispersive X-ray (EDX) investigation. Results presented in Fig. 7 show the EDX of the sample A. It shows that the material contains only zinc and oxide.

According to the literature, the growth processes occur as it is shown below [8]:

$$
\begin{aligned}
& \left(\mathrm{CH}_{2}\right)_{6} \mathrm{~N}_{4}+6 \cdot \mathrm{H}_{2} \mathrm{O} \rightarrow 6 \cdot \mathrm{HCHO}+4 \cdot \mathrm{NH}_{3}, \\
& \mathrm{NH}_{3}+\mathrm{H}_{2} \mathrm{O} \leftrightarrow \mathrm{NH}_{4}^{+}+\mathrm{OH}^{-}, \\
& 2 \mathrm{OH}^{-}+\mathrm{Zn}^{2+} \rightarrow \mathrm{ZnO}+\mathrm{H}_{2} \mathrm{O} .
\end{aligned}
$$

The addition of the ascorbic acid with dissociation constant $k^{l}=7.94 \times 10^{-5}$ to the solution with urea and HMT should not change the acid alkali balance. However, this chemical compound has the influence on the shape and adhesion of the nanostructure to the substrate. The explanation of the growth process will be performed in the future work.

\section{Conclusions}

The influence of the chemical compounds in the solution on the $\mathrm{ZnO}$ crystal growth was investigated. The experiments have shown that small addition of the or- ganic compound, namely ascorbic acid $\left(1.5 \times 10^{-5} \mathrm{~mol}\right.$ into $250 \mathrm{ml}$ of $\mathrm{H}_{2} \mathrm{O}$ ) change the shape of the structure and decrease its adhesion to the substrate. The samples, where the HMT was replaced with urea, are different than $\mathrm{ZnO}$ structures obtained in the classical way in $\mathrm{CBD}$, like in sample A. The structures are not equivalent to $\mathrm{ZnO}$ wurtzite type crystal and to any structure of zinc hydroxide. The presented results are the preliminary investigations, which have the goal to define the influence of the different chemical compounds on the nanocrystal growth in CBD. In the future investigation the mechanism of the deposition process in the solution with urea and ascorbic acid should be explained.

\section{Acknowledgments}

This work was sponsored by EU project no. POIG.01.03.01-02-002/08-00 from the date 15.12.2008 "Detectors and sensors for measuring factors hazardous to environment - modeling and monitoring of threats".

\section{References}

[1] M.H. Huang, S. Mao, H. Feick, H. Yan, Y. Wu, H. Kind, E. Weber, R. Russo, P. Yang, Science 292, 1897 (2001).

[2] H. Guo, J. Zhou, Z. Lin, Electrochem. Commun. 10, 146 (2008).

[3] K. Ogata, K. Koike, S. Sasa, M. Inoue, M. Yano, Applied Surface Science 254, 7708 (2008).

[4] Y. Yan, Y. Zhang, G. Meng, L. Zhang, J. Cryst. Growth 294, 184 (2006).

[5] W. Sang, Y. Fang, J. Fan, Y. He, J. Min, Y. Qian, J. Cryst. Growth 299, 272 (2007).

[6] J. Yang, J. Lang, L. Yang, Y. Zhang, D. Wang, H. Fan, H. Liu, Y. Wang, M. Gaoa, J. Alloys Comp. 450, 521 (2008).

[7] P. Hari, M. Baumer, W.D. Tennyson, L.A. Bumm, J. Non-Cryst. Solids 354, 2843 (2008).

[8] Q. Li, V. Kumar, Y. Li, H. Zhang, T.J. Marks, R.P.H. Chang, Chem. Mater. 17, 1001 (2005), DOI: $10.1021 / \mathrm{cm} 048144 q$, Publication Date (Web): 03 February 2005.

[9] M. Byrczek, P. Hari, J. Donaldson, H. Teterycz, Investigation of Zinc Oxide Nanorods Growth on ITO Coated Glass Substrates, ISSE, Brno 2009.

[10] M. Byrczek, M. Malewicz, H. Teterycz, "Growth of Zinc Oxide 1D Nanostructures on the Zinc Oxide Thin Film by Chemical Bath", 2009 International Students and Young Scientists Workshop "Photonics and Microsystems", 2009.

[11] M. Malewicz, M. Byrczek, H. Teterycz, "Temperature as a Significant Determinant in Zinc Oxide 1D Nanostructures", 2009 International Students and Young Scientists Workshop "Photonics and Microsystems", 2009 . 